\title{
Data Analysis of Precipitation Hardening of Al-Cu Alloy through Fuzzy Monitoring Approach
}

\section{Vafaeenezhad $\mathrm{H}^{1}$ and Ghomaishi $\mathbf{M}^{2^{*}}$}

${ }^{1}$ Materials Processing Simulation Laboratory (MPS-Lab), School of Materials and Metallurgical Engineering, Iran University of Science and Technology (IUST), Narmak, Tehran, Iran

${ }^{2}$ Turbo Compressor Engineering and Design Centre, Oil Turbo-Compressor Holding (OTC), Tehran, Iran

"Corresponding author: Ghomaishi M, Turbo Compressor Engineering and Design Centre, Oil Turbo-Compressor Holding (OTC), Tehran, Iran, Tel: +98 919 508674; Email: mostafa.ghomeishi@gmail.com

Received date: July 31, 2016; Accepted date: August 1, 2016; Published date: August 11, 2016

Copyright: (c) 2016 Vafaeenezhad H, et al. This is an open-access article distributed under the terms of the Creative Commons Attribution License, which permits unrestricted use, distribution, and reproduction in any medium, provided the original author and source are credited.

\section{Introduction}

Prediction of the material behavior after heat treatment is a necessary step to optimize the design of any industrial part. As a sample, a soft computational approach was implemented using the linguistic ability of fuzzy logic systems as a powerful tool for predicting the hardness of solid solution aluminum alloy during precipitation hardening to determine the optimal hardness.

It is often necessary to perform a heat treatment that aluminum alloys can be used for modern advanced applications. That is to say that the most pertinent and effective way to improve the mechanical properties of $\mathrm{Al}$ alloys is precipitation hardening. Precipitation hardening of $\mathrm{Al}$ alloys requires high quench rate after solution annealing to avoid coarse intermetallic precipitates formation at the grain boundaries. A supersaturated solid solution of alloying elements is a pre-requisite for the formation of fine intermetallic precipitates during aging, which improves the strength of the material.

When $\mathrm{Al}$ alloys are solution heat treated at elevated temperatures, the alloying elements are solved in the $\mathrm{Al}$ crystal lattice. During aging treatment, alloying elements formerly solved in the $\mathrm{Al}$ rich matrix exit and form intermetallic components that subsequently cause hardening elements precipitate in localized areas resulting in a significant increase in the strength [1].

Considering the diffusion of the alloying elements as a necessary factor for precipitation, heating activation is known as imperative factor for quick forming of precipitates. Furthermore, there are different parameters, which affect mechanical properties of the alloy such as time and temperature of the solution heat treatment, time and temperature of the aging treatment as well as the cooling rate of the alloy during quenching stage. An appropriate combination of aging treatment time and temperature can cause a superior property in this alloy [2].

Nowadays, novel soft computational methods and artificial intelligence approaches have found their place in materials science and engineering which is due to the fact of narrowing down of the boundaries between different majors in recent researches [3]. Establishing an applied mathematical relation between mechanical property and heat treatment factors, is the kind of problem which is very complex, non-linear and multi-dimensional and in the case, such methodologies shows their potential and power quite better.

In this research, an attempt was made to apply a fuzzy logic (FL), as one of the conventional intelligent modeling techniques, for modeling and evaluation of the materials fabrication factors considering astreated hardness of the heat-treated $\mathrm{Al}$ alloy. Soft computation based on artificial intelligence outlines has shown its capability in advanced engineering materials manufacturing and characterization.

Fuzzy logic theorem was first introduced by Zadeh and later expanded in next decade [4]. This approach is a powerful problemsolving method with many applications in process control challenges and materials fabrication. Fuzzy concepts provide a remarkably easy way for drawing definite conclusions from vague, uncertain and imprecise information.

Fuzziness describes event uncertainty but probability concepts deal with occurrence of events. The degree to which a phenomenon occurs is in FL realm just if its occurrence is random according to probability. Fuzzification is a process that converts numerical data to corresponding fuzzy sets. The rule evaluation step consists of the several "if...then" phrases that forms linguistic structure of the rules. Finally, a defuzzification step transforms the fuzzy outputs to crisp ones $[5,6]$.

\section{Al-Cu Alloy}

The present study, evaluates the effect of precipitation hardening parameters such as aging temperature (AT.), aging time (At.) and solution time (St.) on hardness (H.) of heat-treated aluminum-copper alloy. Initially to achieve maximum uniformity in the grain dimensions, structure and strain distribution, a primary annealing heat treatment was performed at temperature of $404^{\circ} \mathrm{C}$ for $2 \mathrm{~h}$. The main heat treatment strategy was carried out according to the following strategy; each group was heated to $496^{\circ} \mathrm{C}$ for $25 \mathrm{~min}, 45 \mathrm{~min}$ and 65 min, respectively. Afterwards, the samples were quenched in agitated water with temperature of $15^{\circ} \mathrm{C}$. Subsequently, heated alloys were aged at three different temperatures of $140^{\circ} \mathrm{C}, 175^{\circ} \mathrm{C}$ and $210^{\circ} \mathrm{C}$ for $4 \mathrm{~h}, 17 \mathrm{~h}$ and $24 \mathrm{~h}$ to investigate the effect of aging time on strength of the alloy in term of hardness. Figure 1 shows the heat treatment setup for the samples used in this study. Finally, after aging treatment, Brinell hardness test was performed to evaluate the average hardness of the heat treated samples.

The first phase in the fuzzy system design is assigning a symmetrical or an asymmetrical membership function to each variable. In the present work, we have chosen triangular fuzzy sets, as they are commonly applied which is due to their ability for modeling nonlinearity. 
Citation: Vafaeenezhad H, Ghomaishi M (2016) Data Analysis of Precipitation Hardening of Al-Cu Alloy through Fuzzy Monitoring Approach. Int

Page 2 of 3

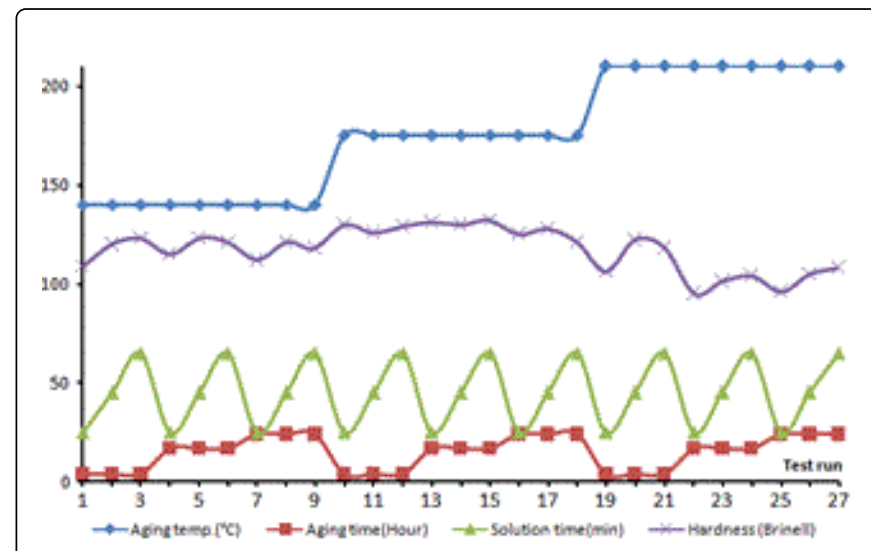

Figure 1: Experimental design for the heat treatment study.

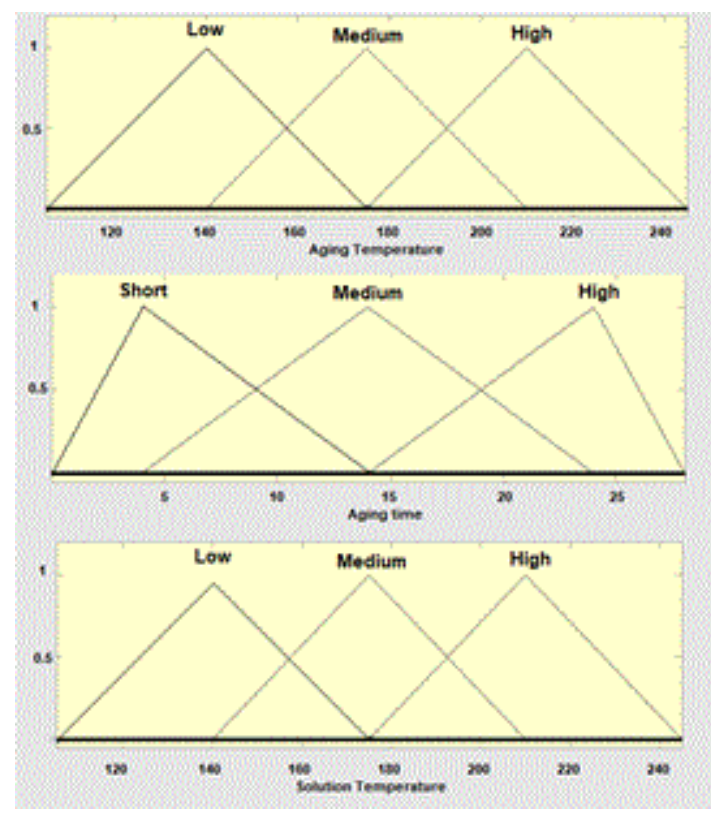

Figure 2: Membership function for three inputs.

Fuzzy membership converts the notion of binary membership to various degrees of membership values on a two dimensional diagram. Figures 2 and 3 illustrate the shape and range of each membership function for inputs and output variables.

The goal is to establish a connection between multiple inputs and final hardness. Table 1 shows 16 defined rules. Inference system and defuzzification are the ending process in the FL analysis, subsequently. Many defuzzification methods can be used such as center-of-area, weighted average. Fuzzy model results and hardness number values of experimental tests were assessed by a regression graph in Figure 4 to evaluate the efficiency of fuzzy model in prediction of the mechanical property.

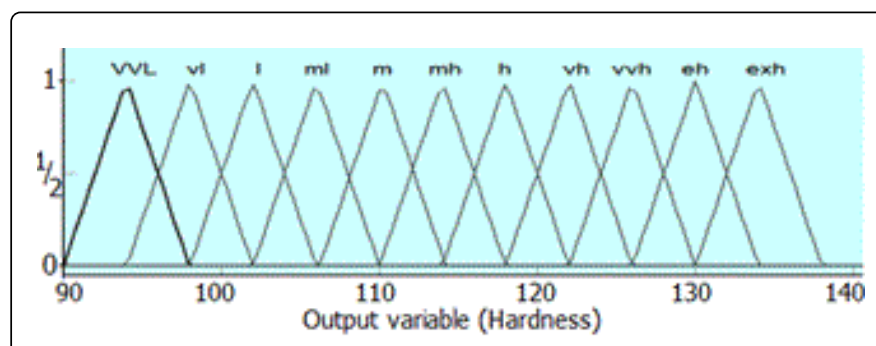

Figure 3: Membership functions for one output.

If (AT. is Low) \& (At. is Short) \& (St. is Low) then ( $\mathrm{H}$. is vvl)

If (AT. is Low) \& (At. is High) \& (St. is Mid) then ( $\mathrm{H}$. is $\mathrm{vl})$

If (AT. is Low) \& (At. is Short) \& (St. is High) then (H. is vl)

If (AT. is Mid) \& (At. is Short) \& (St. is Mid) then (H. is $\mathrm{ml})$

If (AT. is Mid) \& (At. is Mid) \& (St. is Mid) then (H. is I)

If (AT. is Mid) \& (At. is High) \& (St. is High) then (H. is $m$ )

If (AT. is Mid) \& (At. is Mid) \& (St. is Mid) then (H. is I)

If (AT. is High) \& (At. is Short) \& (St. is Low) then (H. is vh)

If (AT. is High) \& (At. is Short) \& (St. is High) then (H. is vh)

If (AT. is Low) \& (At. is Mid) \& (St. is High) then (H. is m)

If (AT. is High) \& (At. is High) \& (St. is High) then (H. is exh)

If (AT. is High) \& (At. is High) \& (St. is Mid) then (H. is eh)

If (AT. is High) \& (At. is Mid) \& (St. is High) then (H. is vvh)

If (AT. is High) \& (At. is Short) \& (St. is Low) then ( $\mathrm{H}$. is $\mathrm{mh}$ )

If (AT. is Mid) \& (At. is Short) \& (St. is Low) then (H. is I)

If (AT. is Low) \& (At. is High) \& (St. is High) then (H. is mh)

Table 1: Linguistic rules definition for FL inference system.

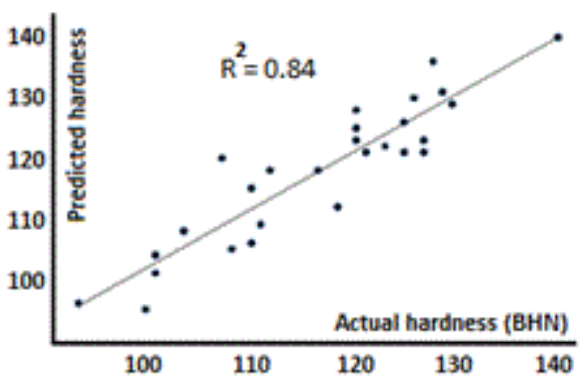

Figure 4: Regression graph for FL hardness prediction. 
Citation: Vafaeenezhad H, Ghomaishi M (2016) Data Analysis of Precipitation Hardening of Al-Cu Alloy through Fuzzy Monitoring Approach. Int J Sens Netw Data Commun 5: e109. doi:10.4172/2090-4886.1000e109

Page 3 of 3

Results show that the FL system is capable of predicting the nonlinear and complex behavior of heat treated Al-Cu alloy. The fuzzy model was used successfully for establishing a relation, as a fitness function for further optimization process, between the desired output and three affecting input parameters.

\section{References}

1. Mackenzie DS, Totten GE (2003) Handbook of aluminum (eds.) Marcel Dekker Inc

2. Meyveci A, Karacan İ, Çalıgulu U, Durmuş H (2010) Pin-on-disc characterization of $2 \mathrm{xxx}$ and $6 \mathrm{xxx}$ aluminium alloys aged by precipitation age hardening. J Alloys Compd 491: 278-283.
3. Ghomeishi M, Mahdiraji GA, Jahanshahi P, Adikan, FM, Bradley DA (2015) Study of Traps in Special Doped Optical Fiber Radiation Sensors via Glow Curve Analysis. Int J Sens Netw Data Commun 4: 1-4.

4. Zadeh LA (1965) Fuzzy sets. Inform Control 8: 338-353.

5. Vafaeenezhad H, Zebarjad M, Khaki JV (2013) Intelligent modeling using fuzzy rule-based technique for evaluating wood carbonization process parameters. Int J Adv Manuf Tech 68: 1471-1478.

6. Ghanei S, Vafaeenezhad H, Kashefi M, Eivani AR, Mazinani M (2015) Design of an expert system based on neuro-fuzzy inference analyzer for online microstructural characterization using magnetic NDT method. J Magn Magn Mater 379: 131-136. 